J Urol Nephrol

March 2018 Vol.:5, Issue:1

(C) All rights are reserved by Agzamkhodjaev ST,et al.

\title{
Early Surgical Correction of Ureteropelvic Junction Obstruction
}

\begin{abstract}
Based on the analysis of 131 (from month 1 to 3 years old) children with Ureteropelvic Junction (UPJ) obstruction, who underwent early pyeloplasty, it was found that the incidence of intra and postoperative complications in both groups remains identical.

Good and satisfactory results obtained from Group I (91) in 89 (98\%) patients, and from Group II (40) in 38 (95\%) children proved high efficiency of surgical treatment and the expediency of early pyeloplasty. Based on this research, it may be concluded that, it is baseless to prolong children observation with congenital hydronephrosis, in orde to prevent intra- and postoperative complications associated with early children age. In turn, early correction of obstruction of UPJ, in the absence of infection, leads to the preservation of kidney function and creates optimal conditions and prerequisites for the development and growth of functional structures.
\end{abstract}

\section{Introduction}

Antenatal diagnosis of upper urinary tract dilatation ratio is 1:500, however, in fact, number of surgeries related to that still relatively small and is about 1:1250-1500.

Postnatal management of antenatally diagnosed hydronephrosis is staying in continuous controversial state [1-3]. Ruiz et al. as he performed comparison early pyeloplasty with delayed surgery, came to conclusion that early surgical intervention in the period of infancy better preserve renal function in children [4,5]. But, Onen et al. in their research performed dynamic observation of children with Uereteropelvic Junction Obstruction (UPJO), where 25 patients' kidneys where improved during 2-year observational nonintervention study [6].

Further investigations needed to discuss functional results of surgical treatment of ureteropelvic junction obstruction at early stage and delayed period. We performed research to find out if there is a difference in outcomes between infants and older children after surgical treatment [7].

\section{Material and Methods}

Research covered diagnostic and surgical correction data analysis of 129 children treated in the department of pediatric urology between 2013 and 2017. 40 (31\%) patients had right side UPJO, left sided obstruction was in 63(49\%), and 26 (20\%) had bilateral lesion.

Patients age who underwent surgical treatment ranged from 1 month to 3 years, mean age was 10 month. Subjects were divided into 2 study groups: I group included children of age between 1 month and 1 year; patients of 1-3-year age, who surgically treated were in Group II. Male to female ratio was $100(78 \%)$ to $29(22 \%)$ respectively, male predominance was in both groups.

Preoperative assessment was intended for non-obstructive hydronephrosis exclusion. All patients evaluated with ultrasound

\section{Journal of \\ Urology \& Nephrology}

\author{
Agzamkhodjaev ST*, Abdullaev ZB, Sanginov ShA \\ and Umargaliev SD
}

Tashkent Pediatric Medical Institute, Republic of Uzbekisatn

\section{Address for Correspondence}

Agzamkhodjaev Saidanvar Talatovich, Tashkent Pediatric Medical Institute, Tashkent City, 100140, Republic of Uzbekisatn, Tel: +99897 420-30-03; E-mail: ast.doctor@gmail.com

Abdullayev Zafar Bobirugli, Tashkent Pediatric Medical Institute, Tashkent City, 100140, Republic of Uzbekisatn, Tel: +998909099911; E-mail: abdullaev.z880@gmail.com

Submission: 02 January, 2018

Accepted: 16 March, 2018

Published: 22 March, 2018

Copyright: () 2018 Agzamkhodjaev ST, et al. This is an open access article distributed under the Creative Commons Attribution License, which permits unrestricted use, distribution, and reproduction in any medium, provided the original work is properly cited.

imaging, intravenous pylography, diuretic renographyand laboratory tests.

The most prevailed clinical presentation of UPJO was nonsymptomatic type in 114 patients (88\%), 75 of them had diagnosed antenatally and in 39 Pyelourethral Junction (PUJ) obstruction was found accidently during routine peritoneal and retroperitoneal spaceultrasound. Typical clinical sign of congenital anomaly in 2 (1.5\%) cases was disturbed condition with no exact local complaints, which was stated as pain syndrome. Urinary tract infection was reason for ultrasound check in $11(8 \%) .2(1.5 \%)$ had condition assessment because of palpable mass in abdominal area. There were no complains for hematuria in patients we tested.

Characteristic of clinical manifestation was different in each age group and shown in Table 1.

All patients who had UPJO stage III and IV (Society for pediatric urology classification) underwent pyeloplasty. If complex hydronephrosis with renal parenchymal thinning and when no contrasted collecting system was found, percutaneous nephrostomy tube was inserted. Whereas children with I and II grade UPJO were advised follow up repeated ultrasound scan in 3-6 weeks. If condition worsening noted-enlargement of anteriorposterior pelvic size, thinning of kidney parenchyma, then patient underwent pyeloplasty. When negative clinical dynamic was absent, dynamic renoscintigraphy with MAG3 was conducted. Children with obstruction, demonstrating obstructive curve type: renal differentiating function lower $40 \%$, also underwent pyeloplasty.

Table 1: Characteristic of clinical manifestation was different in each age group.

\begin{tabular}{|l|c|c|c|c|c|c|c|c|}
\hline \multirow{2}{*}{ Groups } & \multicolumn{3}{|c|}{ Non-symptom } & \multicolumn{2}{c|}{ Palpable Mass } & \multicolumn{2}{c|}{ UTI } & \multicolumn{2}{c|}{ Abdominal Pain } \\
\hline & Abs & $\%$ & Abs & $\%$ & Abs & $\%$ & Abs & $\%$ \\
\hline Group 1 & 85 & 66 & 1 & 0,8 & 6 & 4,5 & - & - \\
\hline Group 2 & 29 & 22 & 1 & 0,8 & 5 & 3,5 & 2 & 1,6 \\
\hline All & 114 & 88 & 2 & 1,6 & 11 & 8 & 2 & 1,6 \\
\hline
\end{tabular}


Where patients have improved renal function, in pelvic size with absent clinical manifesting during assessment period did not undergo surgical correction, and were excluded from this study.

Dismembered pyeloplasty with modification was performed in all patients. Surgical approach carried out intramuscularly in lumbar area. During surgical correction, all patients had PUJ resection following morphological assessment. Resection of pelvic was performed only in cases of massive dilatation of collecting. Postoperatively, for 7-8 days, collecting system was drained with intubating pyelostomy. All patients received antibiotic therapy for 7 days after surgery.

All patients followed checkup after 3, 6 month and 1, 3 years after surgical treatment. We performed lab tests and US scan to assess dynamics of collecting system dilatation, kidney improvement and parenchymal recover. Intravenous urography performed after 6 month of surgery to study morph-functional state of affected kidney and upper urinary tract. Assessment of differential function made after 1 year through diuretic renogram.

All results of surgical PUJ correction depending on achieving or unchanged state of urodynamic recover divided in three categories: conditions evaluated as good, satisfactory and non-satisfactory results.

Good results were evaluated as satisfactory when there were absence of pathologic changes in urine tests, clinic manifestation development as pain syndrome, improved collector segment size on US scan, urine excretory function recover and improvement in differential renal function.

Satisfactory group characterized with transitional changes in urine tests, periodical clinic symptoms and complaints, slightly or practical unchanged collector system of kidney and excretory function.

In non-satisfactory group noted pyelonephritis exacerbation, worsening dilatation of collecting system with damaged kidney blood supply, non-recovered evacuation of contrast media and differential renal function on diuretic renogram.

\section{Results and Discussion}

One hundred thirteen pyeloplasty procedures were performed in 92 infants in Group I ( 21 bilateral) and 42 procedures in 37 patients in Group II (5 bilateral). All surgeries went well without intraoperative complications. No case has held hemotransfusion intraand postoperatively. Despite fact that children were in small age and infant type body development, there was no obvious difference in results between I and II group. Clinical manifestation of urinary tract infection was observed in $4(4 \%)$ and only $1(2 \%)$ patient in group I and II respectively. In postoperative period of Group I, 4 patients had a complication, which is corresponded to grade I in P. Clavien's classification. In comparision, group II had slightly lower complication rate (2\%), however it did not reach statistical significance. In addition, performed pyeloplasty on infants in first group did not affected patient's hospital stay (mean $5+2$ days). If good and satisfactory results were achieved in 89 of 92 (97\%) patients of Group I, the same results were in Group II as 35 of 37 (95\%).

In conclusion, our conducted research shows, long observation and delayed surgical intervention to prevent intra- and postoperative complication are lacking substantial proof. Furthermore, analysis let us to think that performing pyeloplasty at early stage of UPJO in younger age, when is not complicated with infection leads keeping good renal function and creates best condition for further development and growth of functional structures.

\section{References}

1. Hubert KC, Palmer JS (2007) Current diagnosis and management of fetal genitourinary abnormalities. Urol Clin North Am 34: 89-101.

2. Bajpai M, Chandrasekharam VV (2002) Nonoperative management of neonatal moderate to severe bilateral hydronephrosis. J Urol 167: 662-665.

3. Menon P, Rao KL, Bhattacharya A, Mittal BR (2016) Outcome analysis of pediatric pyeloplasty in units with less than $20 \%$ differential renal function. $J$ Pediatr Urol 12: 171

4. Capello SA, Kogan BA, Giorgi LJ Jr, Kaufman RP Jr (2005) Prenata ultrasound has led to earlier detection and repair of ureteropelvic junction obstruction. J Urol 174: 1425-1428.

5. Ruiz E, Soria R, Ormaechea E, Lino MM, Moldes JM, et al. (2011) Simplified open approach to surgical treatment of ureteropelvic junction obstruction in young children and infants. J Urol 185 (6 Suppl): 2512-2516.

6. Onen A (2006) The natural history and therapeutic approach of antenatally diagnosed primary UPJ-type hydronephrosis. Turkish J Pediatr Surg 20: 3338.

7. Fernbach SK, Maizels M, Conway JJ (1993) Ultrasound grading of hydronephrosis: Introduction to the system used by the society for Fetal Urology. Pediatr Radiol 23: 478-480. 